\title{
DISCUSSION ON PAPER 8540
}

\section{Analysis of composite girders with deformable connectors}

\section{Křistek and J. Studnička}

Dr D. S. Prakash Rao, Structural Engineering Research Centre, Roorkee, India

The Authors must be commended for their new approach to the problem of deformable connectors and for presenting an elegant solution to the computation of stresses and deformations in a composite girder. The degree of composite action is a rather difficult parameter to evaluate and depends on several factors such as the connector modulus, reinforcement layout, quality of concrete, type of loading, as well as bond between steel girder and concrete slab. It can be seen from Fig. 6 that a large variation in the factor $K$ affects the deformation and stresses in a very small way over a large part of the graphs. Even for the flexible shear connectors like the studs considered in the Paper, it is obvious that a large variation in their spacings causes only minor changes in the behaviour of the composite beam. For other types of rigid and semi-rigid connectors this effect is likely to be even less pronounced. A considerable degree of composite action exists even when no connectors are provided at the interface between the steel and concrete. This is borne out by several tests on actual bridge structures ${ }^{10}$ and laboratory investigations at the Roorkee Research Centre. The frictional forces at the interface, the bond between steel and concrete and some degree of fixity at the loaded points appear to be the cause of this phenomenon. In the Paper, this factor has been omitted, although it can be incorporated if experimental values are available. This would further reduce deformability characteristics of the shear connectors and the actual deformations will be smaller than theoretical values.

44. Could the Authors supply a small clarification regarding $A_{\mathrm{c}, n}=b_{n} t$, where $b_{n}$ is given as the effective breadth of the concrete deck corresponding to the $n$th term of Fourier series? Does that mean that the effective width of the concrete deck is to be expressed in Fourier series like the loading $p(x)$ ?

\section{Dr Křístek and Dr Studnička}

It is well-known that the effective width of the deck of a beam under loading with a harmonic variation $\left(p_{1}=\sin \pi x / L\right.$ (Fig. $\left.\left.5(\mathrm{~b})\right)\right)$ is constant over the length of the span $L$. It holds the following formula

$$
b_{1}=\frac{4 L}{\pi(1+\gamma)(3-\gamma)}
$$

in which $\gamma$ is the Poisson's coefficient. For the concrete deck $(\gamma=0.15), b_{1}=$ 0.389L. The beam with loading expressed by the $n$th harmonic $\left(p_{n}=\sin n \pi x / L\right)$

Paper published: Proc. Instn Civ. Engrs, Part 2, 1982, 73, Dec., 699-712. 
behaves as a system of identical girders of spans $L_{n}=L / n$ with the effective widths $b_{n}=b_{1} / n$. Thus, to each individual harmonic belongs a corresponding effective width of the concrete deck.

46. This is also the reason why the effective width decreases rapidly in the regions of point loads or support reactions for whose satisfactory expression a higher number of harmonic is necessary.

\section{References}

10. RAO D. S. Prakash et al. In situ testing of bridges. Structural Engineering Research Centre, Roorkee, India, 1983. Research Report.

11. Girkmann K. Flächentragwerke. Springer, 1963. 